\title{
Study of Rail Freight Capacity Release in the Typical Existing Trunk After the Completion of High-Speed Railway
}

\author{
H.Y. Li \\ School of Traffic and Transportation \\ Beijing Jiaotong University \\ Beijing, China \\ 635435527@qq.com
}

\author{
Y. Li \\ School of Civil Engineering \\ Shijiazhuang Tiedao University \\ Shijiazhuang, Hebei \\ 1204043441@qq.com
}

\begin{abstract}
After the completion and operation of the HSR (short for high-speed railway), a portion of passenger train flows in the existing parallel lines will transfer to the HSR, which is going to bring changes in the structure of train operation diagram, influences the carrying capacity of existing lines and releases the freight capacity of the network as well. This paper adopts the improved deduction coefficient method to calculate the releasing value of freight capacity in two cases, namely the decentralized dispatching and the continuous dispatching. Compared with the traditional deduction coefficient method, the result of the improved method is closer to the practical freight capacity. Taking Wuhan-Guangzhou segment of BeijingGuangzhou high-speed railway for example, this paper quantifies the releasing value of freight capacity of Wuhan-Guangzhou segment belonging to the existing line based on comparative analysis of the number of passenger trains before and after the opening of the high-speed railway
\end{abstract}

Keywords - the existing line; rail freight capacity release; the improved deduction coefficient method

\section{INTRODUCTION}

For a long time, the existing busy trunk of China's railway network has been in an overload state. According to the data released by the authorities in recent years, the overall satisfaction rate of train utilization demand is only $35 \%$, and the capacity utilization rate of some segments of BeijingGuangzhou line and Beijing-Shanghai line has already reached $100 \%$. A large amount of goods flow shift to road transport, which not only increases freight costs, but also adds pressure to road transport. With the opening and operation of high-speed railway, freight capacity of existing lines get some released. As the extent of the cargo capacity release has a direct impact on the utilization of the transport capacity of the existing lines, it is of great significance to conduct the research of freight capacity release of typical existing trunk after the completion of the high-speed railway.

\section{RESEARCH THINKING}

Railway Section Capability means the maximum number of trains (the number of columns or pairs) that goes through the section within a day and night in every interval of railway section under some certain operation organization conditions [1]. Cargo capacity release value is the increased number of new-opening cargo trains or pairs in existing trunk parallel to the high-speed rail, as some train flows get transferred after the completion of high-speed railway. So far, there are two main types of methods to calculate the Railway Section Capability: graphic method and analysis method.

At the first step, the graphic method is to paint passenger trains in the operation diagram, then paint freight trains in the intervals of passenger trains. The objective is to maximize the number of trains, both passenger trains and freight trains, painted in the diagram. This program is intuitive, accurate, but requires a lot of data to support and artificial experience [2]. And once the operation demand changes, the painting program needs to be re-adjusted accordingly, so it is difficult to grasp the changes in the carrying capacity value of lines at the macro.

As graphical method is relatively cumbersome, the analysis method is preferred to compute the carrying capacity of the non-parallel diagram. The deduction coefficient method is one of the traditional analysis methods to calculate the carrying capacity of railway segments. To acquire the specific value of this kind of capacity in non-parallel operation diagram, we can calculate the number of freight trains that need to be transferred to spare capacity for one passenger train, which is based on the parallel operation diagram. The accuracy of the result calculated by this analysis method depends on the reasonableness of the deduction coefficient. As the traditional deduction coefficient method is based on general freight trains, the accuracy of the outcome will decrease with the increase of passenger trains [3].

In this paper, we estimate the released ability value on existing lines as a result of passenger transfer after the completion of high-speed railway by the improved deduction coefficient method. Compared with the traditional deduction coefficient method, we conclude that the released value of cargo capacity calculated by improved deduction coefficient is more realistic. 


\section{Determination OF the RELEASEd VALUe of CAPACity ON THE EXISTING LINE}

\section{A. Determination of the Shunting Number of Passenger Trains}

The following two aspects can be considered separately to determine the number of passenger trains shunting on the existing line:

- For the existing segments parallel to a high-speed railway, we can determine the number of passenger trains out of service, namely the shunting number, by querying the national railway train schedules before and after the completion of the high-speed railway;

- $\quad$ For the segments parallel to the high-speed railway still under construction, we need to predict the number of passenger trains that are out of service. First, according to the relevant policies, such as the principles about the proportion of various passenger trains that will be shut down in some district, we can deduce the approximate number of trains out of operation. Without the support of relevant policies, we can refer to the proportion of the lines in operation which is similar to the line we are researching in various aspects, or we can apply the polices designed for other similar but unopened lines to our target line [4].

\section{B. Calculating Released Value of Cargo Capacity with an Improved Deduction Coefficient Method}

When the proportion between the passenger trains in continuous dispatching and the trains in decentralized dispatching increases, the result of the traditional deduction coefficient method will be larger than the real value, which will definitely affect the development of rail freight production plan. So the improved deduction coefficient method should be applied by two cases [5]:

\section{- $\quad$ Passenger trains in decentralized dispatching}

Deduction coefficient refers to the number of freight trains deducted from the parallel operation diagram because of painting a pair of or a passenger train, fast freight train or pickup goods train. The formula is as follows:

$$
\varepsilon_{F}=t_{F} / I=\frac{I_{A-T}+I_{T-L}+t_{S-S}+1.025 t_{D}-1.4}{I}+0.05-0.037 t_{D}
$$

$I_{A-T}, I_{T-L}$ is arrival-through time and through-leave time for passenger train passing through freight train; ${ }^{t_{-S}}$ is additional time because of the train's start and stop; ${ }_{D}$ is the deviation of arriving time in a station of freight trains and passenger trains in a limited section.

Through the above calculation, the deduction coefficient of each passenger train can be got, when the passenger train is decentralized dispatching, the calculation formula of the capacity release is:

$$
n_{I N C}^{1}=\sum_{i \in I} \varepsilon_{i} n_{i}=\varepsilon_{N} n_{N}+\varepsilon_{K} n_{K}+\varepsilon_{T} n_{T}+\varepsilon_{Z} n_{Z}+\varepsilon_{D} n_{D}
$$

In the formula, $I$ is the set of the types of passenger train transferred from the existing line; $n_{i}$ is the number of canceled passenger trains; $\varepsilon_{i}$ is the deduction coefficient of the passenger train of the existing line.

\section{- $\quad$ Passenger trains in continuous dispatching}

When passenger trains dispatch continuously, two tracking passenger trains take only a tracking interval time. Between two passenger trains no freight train can be drawn, and the time is too smaller than $t_{F}$, so the tracking drawing of passenger train can reduce the deduction time. At the same time, the influence range of two passenger trains are partially overlap, the deduction time is reduced. So through the analysis of the influence range of tracking train, the value of freight train influenced by grouped tracking passenger trains can be calculated. The calculation formula is

$$
n_{I N C}^{2}=\frac{\sum \Delta t_{R T}}{I}
$$

In the formula, when the number of canceled passenger trains $\Delta n_{F}\left\langle n_{F}\right.$, there is at least 1 tracking passenger train remained, then

$$
\Delta t_{R T}=\Delta n_{F} I_{T T}
$$

When the number of canceled passenger trains $\Delta n_{F}=n_{F}$, there is no grouped tracking passenger train remained in the interval, then

$$
\Delta t_{R T}=t_{B}+t_{W}+\left(\Delta n_{F}-1\right) I_{T T}
$$

In the formula, $I_{T T}$ is the train tracking interval time of grouped tracking train; $\Delta t_{R T}$ is releasing time of diagram; $t_{B}$ is the basic deduction time of passenger train; $t_{W}$ is the wasting time of passenger train.

To sum up, the formula of releasing freight capacity of existing railway by the improved deduction coefficient method is $n_{I N C}=n_{I N C}^{1}+n_{I N C}^{2}$.the improved method avoids effectively the experience algorithm for tracking or consecutive trains by the traditional deduction coefficient method, and improves the accuracy of capacity.

\section{CASE ANALYSIS}

Beijing-Guangzhou high-speed railway is an important "vertical" of "Four vertical and four horizontal" high-speed railway in "Long Term Railway Network Plan (2008 adjusted)" of China. Taking Wuhan-Guangzhou section (Wuhanbei-Hankou-Wuchangnan-Puqi-Yueyangbei-Changsha dong-Zhuzhou-Hengyang-Binzhou-Pingshibei-Shaoguandong- 
Guotang-Guangzhou) which went into operation in 2009 for example, this paper quantifies the releasing condition of the capacity of the existing line Beijing-Guangzhou railway.

According to the relevant documents, we can get the utilization of the capacity of Wuhan-Guangzhou line, as shown in Table I. We can see that the utilization of the capacity of each interval of Wuhan-Guangzhou line is almost close to saturation, the utilization of the capacity of six intervals are greater than or equal to $100 \%$. Through consultation and querying related data, Zhuzhou-Hengyang interval is in a limited section, the daily running number of the train is 122.3 pairs, and the length of the interval is $133.8 \mathrm{~km}$, the cycle of the train operation is the largest. According to the "The Table of National Railway Passenger Train Time", the number of canceled passenger train of Wuhan-Guangzhou line can be got, shown in Table II. We set $I=8 \mathrm{~min}, I_{A-T}=6 \mathrm{~min}, I_{T-L}=5 \mathrm{~min}$, $t_{S-S}=5 \mathrm{~min}$.

TABLE I. UTILIZATION STATISTICS OF WUHAN-GUANGZHOU LINE

\begin{tabular}{|c|c|c|c|c|c|}
\hline Section & $\begin{array}{c}\text { Length } \\
\text { of } \\
\text { Sect- } \\
\text { ion } \\
\text { /km }\end{array}$ & $\begin{array}{c}\text { Passen } \\
\text {-ger } \\
\text { Train/ } \\
\text { pairs }\end{array}$ & $\begin{array}{c}\text { Luggage } \\
\text { and } \\
\text { Package } \\
\text { /pairs }\end{array}$ & $\begin{array}{c}\text { Frei- } \\
\text { ght } \\
\text { Train/ } \\
\text { pairs }\end{array}$ & $\begin{array}{c}\text { Utiliza- } \\
\text { tion of } \\
\text { Parallel } \\
\text { Train } \\
\text { Grape }\end{array}$ \\
\hline $\begin{array}{c}\text { Wuhanbei- } \\
\text { Hankou }\end{array}$ & 31 & 61 & 4 & $47 / 57$ & $96.3 \%$ \\
\hline $\begin{array}{c}\text { Hankou- } \\
\text { Wucangnan }\end{array}$ & 29.5 & $87 / 90$ & 6 & $24 / 15$ & $100.9 \%$ \\
\hline $\begin{array}{c}\text { Wucangnan- } \\
\text { Puqi }\end{array}$ & 117.7 & 51 & 6 & 52 & $93.8 \%$ \\
\hline $\begin{array}{c}\text { Puqi- } \\
\text { Yueyangbei }\end{array}$ & 85.1 & 57 & 0 & 46.3 & $98 \%$ \\
\hline $\begin{array}{c}\text { Yueyangbei- } \\
\text { Changshadong }\end{array}$ & 149.7 & 59 & 0 & 47.5 & $99 \%$ \\
\hline $\begin{array}{c}\text { Changshadong } \\
\text {-Zhuzhou }\end{array}$ & 50.6 & 80 & 0 & 41.9 & $100 \%$ \\
\hline $\begin{array}{c}\text { Zhuzhou- } \\
\text { Hengyang }\end{array}$ & 133.8 & 87 & 0 & 35.3 & $100 \%$ \\
\hline $\begin{array}{c}\text { Hengyang- } \\
\text { Chenzhou }\end{array}$ & 144.6 & 71 & 0 & 45.6 & $100 \%$ \\
\hline $\begin{array}{c}\text { Chenzhou- } \\
\text { Pingshibei }\end{array}$ & 62.5 & 73 & 0 & 42.2 & $100 \%$ \\
\hline $\begin{array}{c}\text { Pingshibei- } \\
\text { Shaoguandong }\end{array}$ & 88.2 & 74 & 0 & 40.5 & $100 \%$ \\
\hline $\begin{array}{c}\text { Shaoguandong } \\
\text {-Guotang }\end{array}$ & 200.8 & 74 & 0 & 37.8 & $100 \%$ \\
\hline $\begin{array}{c}\text { Guotang- } \\
\text { Guangzhou }\end{array}$ & 21.2 & 72 & 0 & 42.2 & $93 \%$ \\
\hline
\end{tabular}

TABLE II. STATISTICS OF THE NUMBER OF STOPPED PASSENGER TRAIN FROM WUHAN TO GUANGZHOU

\begin{tabular}{|c|c|c|c|c|}
\hline & $\begin{array}{c}\text { Express } \\
\text { Train(T) }\end{array}$ & $\begin{array}{c}\text { Fast } \\
\text { Train(K) }\end{array}$ & $\begin{array}{c}\text { Ordinary } \\
\text { Train }\end{array}$ & Subtotal \\
\hline Before Open & 15 & 10 & 2 & 27 \\
\hline After Open & 6 & 2 & 0 & 8 \\
\hline $\begin{array}{c}\text { The Canceled } \\
\text { Number }\end{array}$ & 9 & 8 & 2 & 19 \\
\hline
\end{tabular}

A. The released value of cargo capacity calculated by the traditional deduction coefficient method

According to (1), the deduction coefficient of each passenger train can be calculated, that is $\varepsilon_{T}=2.28, \varepsilon_{K}=2.19$, $\varepsilon_{N}=2.02$. According to (2), the releasing value of cargo capacity of Wuhan-Guangzhou can be calculated, this is $n_{I N C}^{1}=2.02 * 2+2.19 * 8+2.28 * 9=42.08$ pairs.

\section{$B$. The released value of cargo capacity calculated by the improved deduction coefficient method}

Based on the improved deduction coefficient method, the number of canceled passenger trains is separately calculated according to the two cases of the decentralized dispatching and the continuous dispatching in the diagram. In order to get the change law of the release of capacity in different tracking proportion, now we take $20 \%, 50 \%, 80 \%$ respectively to calculate the results. If the proportion of express passenger trains and fast passenger trains in canceled trains is about $3: 2, I_{T T}=7 \mathrm{~min}$, the released value of cargo capacity will be as Table III. Obviously, with the increasing of tracking proportion of stopped trains, the releasing section passing capacity presents a decreasing trend, and it will be less than the result calculated by the traditional deduction coefficient method.

TABLE III. The STATISTICS OF RELEASED VALUE OF SECTION CAPACITY UNDER THE CONDITION OF DIFFERENT TRACKING PROPORTIONS.

\begin{tabular}{|c|c|c|c|c|c|c|}
\hline \multirow{3}{*}{ Species } & \multicolumn{6}{|c|}{ Track Proportion } \\
\hline & \multicolumn{2}{|c|}{$20 \%$} & \multicolumn{2}{|c|}{$50 \%$} & \multicolumn{2}{|c|}{$80 \%$} \\
\hline & $T(2)$ & $K(2)$ & $T(6)$ & $K(4)$ & $T(9)$ & $K(6)$ \\
\hline $\begin{array}{c}\text { Dispersion } \\
\text { Drawing }\end{array}$ & 15.96 & 13.14 & 6.84 & 8.76 & 0 & 4.38 \\
\hline $\begin{array}{c}\text { Track } \\
\text { Drawing }\end{array}$ & 1.75 & 1.75 & 5.25 & 3.50 & 7.88 & 5.25 \\
\hline Subtotal & 17.71 & 14.89 & 12.09 & 12.26 & 7.88 & 9.63 \\
\hline Total & \multicolumn{2}{|c|}{32.6} & \multicolumn{2}{|c|}{24.35} & \multicolumn{2}{|c|}{17.51} \\
\hline
\end{tabular}

According to the actual statistical data after the completion and operation of the Wuhan-Guangzhou high-speed railway in 2009 December, the existing line of Wuhan-Guangzhou railway adds 33 pairs of stipulated freight trains, which agrees with the result calculated by the improved deduction coefficient method in the tracking proportion of $20 \%$, while the releasing capacity calculated by the traditional deduction coefficient method is 42.08 pairs, beyond the actual data of $27.5 \%$. Through the analysis, considering the influence of the occupation operation diagram time by different drawing method and the mutual influence of track train, the traditional deduction coefficient method don't calculate deduction coefficient by different cases, it only do the quantitative calculation by the empirical formula, so the calculated value is too large; Quantifying different drawing method by the improved deduction coefficient method respectively, the results are more close to the reality. 


\section{CONCLUSIONS}

After the construction of a large number of high-speed railways, the cargo capacity of China's existing railway network gets a huge release. But the precise released value of cargo capacity of each interval, each section, and each line is still unknown. As the deviation based on the traditional method of deduction coefficient is too large, this paper calculates the newly increased cargo capacity by the improved method of deduction coefficient and obtains more accurate results. Taking Wuhan-Guangzhou railway for example, this paper quantified the released value of cargo capacity of existing railway. This paper has a certain reference value to make full use of the cargo capacity released by the existing railway, to optimize the transport resource allocation, and to develop new products of cargo transport.

\section{REFERENCES}

[1] Y.G. Jia, L.M. Xu. "Study on Influence of High-speed Railway on Section Carrying Capacity of Existing Line,” Trans.. Econ. Res. Inst, vil. 36, pp. 19-25, 2014

[2] H. Yang, S.W. He. Railway Traffic Organization (in Chinese), Beijing: China Railway Publishing House, 2001

[3] Q.L. Kong, Q.B. Liu. Calculation and Strengthen of Railway Transport Capacity (in Chinese). Beijing: China Railway Publishing House, 2006

[4] J.Y. Duan, S.W. He, Y.S. Shen. "Study on the Railway Increasing Freight Carrying Capacity of the Existing Busy Main-line After the Completion of Passenger-only Line.” J. Wuhan U. Technol, col. 36, pp. 378-381, 2012

[5] S.J. Hu, H. Yang, Q.Y. Peng. Organization of the train Operation. Beijing: China Railway Publishing House, 2009 